\title{
On the question of leadership: the postwar Department of Education and Research at the AIA
}

\author{
Avigail Sachs \\ University of California, Berkeley, California
}

\begin{abstract}
In 1946 the American Institute of Architects established a Department of Education and Research $(E \& R)$, under architect Walter A. Taylor. The name given the new department signaled the importance of research for architecture, and the AIA's intended leadership role in promoting researchbased architectural practice. E\&R developed research policies under an advisory board and in 1959 convened a conference on research for architecture, funded by the National Science Foundation. But the AIA never assumed full leadership in research for architecture: The scope of the project was beyond the means of either academia or the profession, and postwar research policies remained decentralized. Although E\&R played a role in directing applied research, academic institutions proved more able to assume leadership of basic research. This history illustrates the complexity of leadership in a field that bridges academia and professional practice, as well as the importance of multiple leadership roles.
\end{abstract}

Conference theme: New methodologies in architectural research

Keywords: AIA, Department of Education and Research, research policy, basic research, applied research

\section{INTRODUCTION}

As the call for papers clearly states, we are currently witnessing a resurgence of critical interest in the idea of research within the profession of architecture. This is not the first time that prominent architects have grappled with defining the knowledge produced by the profession and developing the means to collect and disseminate it. The role of research in architecture was a focal issue for leading thinkers and practitioners during the two decades following World War II.

In 1954, for example, the American Institute of Architects (AIA) published The Architect at MidCentury, a four-year survey of the profession that identified research as one of the most important longrange concerns for the Institute (AIA 1954). Thomas Creighton, editor of the journal Progressive Architecture $(\mathrm{P} / \mathrm{A})$ and a vocal critic of the AIA policies, similarly promoted the idea of research. In his essay Suggested Program for the AIA, Creighton condemned the Institute for almost every failing of the architecture profession, but nevertheless urged it to continue, and expand, its research program (Creighton 1954). Commenting on this discussion, William W. Wurster (Dean of the School of Architecture at the University of California, Berkeley) remarked:

'Research' can have a rich and distinguished meaning if used sparingly enough. There has been a tendency for it to become a "catch word" and everyone recognizes it as one of the glamour girls of today and uses it with undue ease. ... This morning all I should do is express complete agreement with the recommendation but follow it with the word of caution that we must not apply the word 'research' to each tendril of undocumented experience (Wurster 1954).

Indeed, post-war architects tended to use the term "research" to refer to any exploratory thinking connected to architecture and building. Underlying this broad interpretation was a positivist conception of research, as a scientific process yielding objective and generally applicable observations about the world as it is. This conception distinguished "research" quite clearly from design, understood as the formulation of specific proposals for the world as it could be. At the core of this conception was an ambitious vision: "that architecture, properly understood, could and should directly reflect social truths obtained through empirical research," and, moreover, that "this understanding would allow researchers to find law like regularities in human behavior that might then inform an instrumentalist architecture design to produce desirable behaviors" (Vanderburgh and Ellis 2001:110).

This approach promoted an empirical model of practice, prizing knowledge about the real world ("facts") over idealizations and generalizations. More specifically, it implied that only knowledge of the facts can yield overarching generalizations. 
The idea of research thus became a central focus in the larger controversy about modern architecture. Most histories of American architecture focus on the "struggle" between traditionalist and modernist architects, but by the late 1940s architects were essentially engaged in discussion within the modernist "camp" (Anderson 1997). This controversy was publicly enacted in a 1948 symposium organized by Alfred Barr, Jr., at the Museum of Modern Art (MoMA) titled, "What Is Happening to Modern Architecture?" In the museum Bulletin, the symposium participants reported:

\begin{abstract}
The controversy was soon reduced to something much more basic: those who spoke in terms of style and standards, and those who denounced all labels and "isms" as secondary to the problem of production (Barr, Hitchcock et al. 1948).
\end{abstract}

With its pragmatic implications, "research" in architectural discourse was linked to notions of regionalism, social reform and collaborative practice. Walter Gropius, as professor of architecture at the Graduate School of Design (GSD) at Harvard, clearly recognized these connections:

\begin{abstract}
All in all the emphasis of my arguments is on the creative factor. That is, that a program of search rather than research makes the creative architect. Such a program, I believe, would lead the potential architect from observation to the delight of discovery and invention, and finally to an intuitive shaping of the American scene (Gropius 1951).
\end{abstract}

By the mid $20^{\text {th }}$ century, "research" also had practical connotations. "Research" referred, sometimes interchangeably, both to the products of scientific, systematic inquiry in the natural sciences and to the technological development of new building systems. It also referred to the social sciences, where the city had become the locus of ground-breaking studies, with an accumulation of arsenals of "unbiased" information seen as relevant to architectural practice (Wright 2008). "Research" also comprised the work of New Deal and wartime housing reformers and planners, who claimed authority over a large portion of building in the US. These projects also had a "research basis," rooted in John Dewey's concept of scientific politics, in which learning from social experiments was regarded as fundamental to the development of a healthy society (Friedmann 1996). The term "research" was thus a powerful concept, capturing the complex mood of anticipation of the postwar period. It signified the enormous prewar changes as well as the promise of the future, and it represented a key concept with which American architects negotiated the changing conditions of their practice.

In the postwar period, the enthusiasm for research included on the one hand the concept of a researchbased practice and on the other the development of academic research for architecture. Practitioners and educators became allies in this broad program, cooperating through correspondence, publications and conferences, but they also vied for leadership in the new field. In 1946, for example, the American Institute of Architects (AIA) established a Department of Education and Research (E\&R) (see Figure 1.) Architect Walter A. Taylor, the Department's first Director, commented that many architects and other professionals "look to The Institute, and particularly to the Department of Education and Research, to create an active program of reporting, investigating and research" (AIA n.d.).

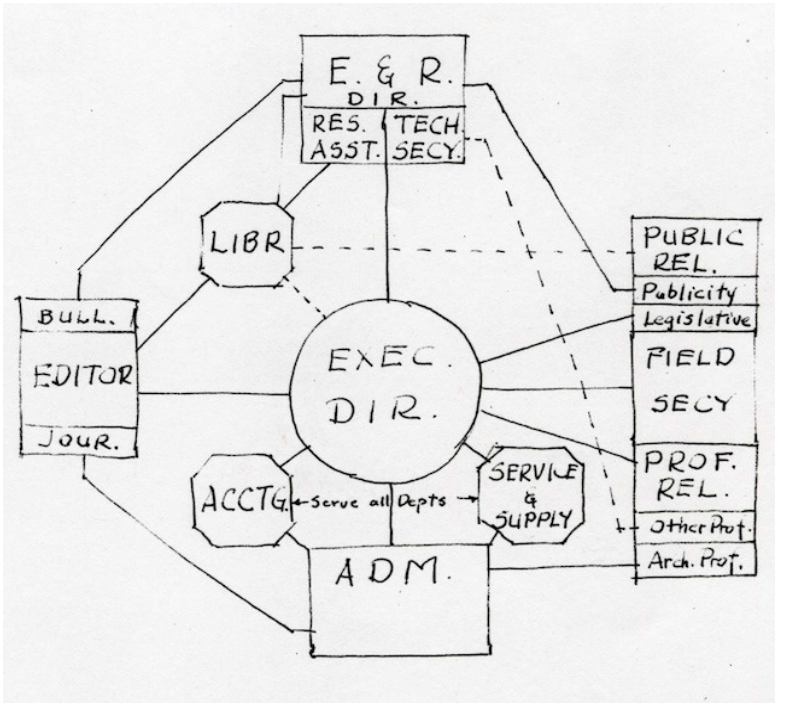

Figure 1: Diagram of structural changes at the AIA 1945. Source: (AIA Archives, Washington, DC)

In the context of the postwar military industrial complex, the question of leadership was essentially moot. The scope of the project of introducing research into architecture was beyond the means of either academia or the profession, and ultimately architects in both spheres assumed leadership for parts of the project rather than its entirety. More importantly, U.S. government research policies promoted a decentralized rather than centralized research effort. Positions of leadership tended to reflect available resources rather than any formal decision or theoretical advantage.

Under Taylor's direction, the E\&R attempted to assume leadership in three spheres: to define architectural research as composite research; to direct applied research and product development; and to outline a program for basic research for architecture. These serious efforts to promote research and architectural practice were supported by practicing architects and academics, but their impact was small. The AIA held little sway in the building industry, and its program for basic research was eclipsed by the accomplishments of the emerging academic discipline.

Current philosophies of knowledge and science are a far cry from the positivist emphasis of the 1950s. But although many postwar research policies have long since been dismantled, research in the United States is still a decentralized endeavour. The history of the Department of E\&R in attempting to steer research in 
architecture demonstrates the importance of multiple leadership roles - and of a model of sharing leadership responsibilities between the academy and the profession.

\section{COMPOSITE RESEARCH}

The public conception of research in postwar USA was shaped by what Roger Geiger has called the ideology of basic research. The premise of this ideology "was that basic research (also called pure or fundamental at the time) was the font of all technological advancement, and that this source was badly in need of replenishment" (Geiger 1993:15). In other words, in order to enjoy the social and economic prosperity warranted by the victory in World War II, America had to invest in the production of scientific knowledge itself - in research conducted by scientists. Once scientists had established this basic body of knowledge, professionals could apply it to social, economic and technological problems for the benefit of society. And indeed, in the twenty years following the war, intellectuals, and especially scientists, were welcomed into the centers of American power and influence and enjoyed an unprecedented status in American society (Bender 1997).

The clear distinction between basic and applied research was a practical as well as philosophical matter, since it played a role in determining research policies in the postwar military-industrial complex. During World War II the federal government had implemented a regimented, centralized model, in which the military, by necessity, set the priorities for research across the US. After the war many Americans, including Senator Harley Kilgore and his colleagues, called for a continuation of this approach. Kilgore argued that if the products of research were to benefit the nation at large, the patents that resulted from federally funded projects should belong to the agency that funded them, and that agency should direct future research. Kilgore worried that a research system that lacked central coordination would allow big business to gain control of the universities and would fail to develop technologies essential for the nation's economic and social welfare (Kleinman 1995). This position emphasized the importance of applied research.

The contrary argument emphasized the importance of basic science. If basic research was the most important intellectual endeavor, then scientists (as experts in science) should be given full responsibility for determining the scope of research projects. Moreover, they should retain the legal rights to their discoveries so that they have the incentive to pursue basic and fundamental questions. This approach was strongly championed by a powerful lobby led by the scientist Vannevar Bush. In his 1945 report, Science the Endless Frontier (Bush 1945), Bush outlined a systematic program for the Federal government, a decentralized model in which individual scientists would assume a leadership role.

American investment in research after the war was large enough to sustain more than one research policy, and the federal government supported a wide range of research projects through several different agencies. Bush and his colleagues, however, were successful in making the scientist-based model the basis of federal policy and introducing the ideology of basic science into American culture (Geiger 1993). This model was compatible with the decentralized system of higher education in the US, with no central agency to direct or standardize universities and technical institutions. In the decade between 1953 and 1963, the federal expenditure for "pure science" rose from half to three quarters of campus budgets (Graham and Diamond 1997). Although most of these funds went directly to principal investigators rather than to the universities, they established what has been called "Big Science": projects requiring big budgets, large staff, elaborate machines and complex laboratories. And they did so, to a large extent, within the universities.

In defining the goals of the Department of E\&R, Taylor took these distinctions into account:

The word "RESEARCH" is so broadly used, so widely abused, that for our purposes it needs to be defined and clarified, or at least classified. The customary over-simplified division into pure and applied science is quite inadequate for our time and our concerns. There are several kinds of activities which various people call "research" - several kinds of searching for knowledge and compiling of information. All of them have some bearing on, or are used in parts of the building industry and architectural design (Taylor 1954).

Taylor proposed a new category of research:
X. Composite, Objective or Creative
Research:
Composite in one or both of the following ways:
a. Two or more basic sciences or applied sciences involved, including more recently social sciences.
b. Two or more basic types of products and/or engineering in combination in a building types or element (Taylor 1954).

Taylor's intellectually ambitious proposition clearly indicated the leadership role he assigned to E\&R. His description positioned research for architecture as a unique enterprise, while emphasizing the creative emphasis in architectural practice. This definition, however, remained largely intellectual. In the polarized climate of the postwar military-industrial complex it proved difficult to garner support and funding for composite projects. While the AIA was willing to support such research itself, Taylor soon realized that the funds needed were beyond the Institute's resources. If the Department of E\&R was to assume leadership it would have to do so within the existing framework - and focus on applied and basic research separately. 


\section{APPLIED RESEARCH}

In the first few years following the end of World War II, the American building industry seemed poised on the brink of a major breakthrough. By transforming the methods of building construction, applied research would in effect unify the small building businesses across the United States into an industry as efficient and as profitable as those glamorous new stars of industry, cars and televisions. The excitement of this vision spurred architects to propose building systems based on materials and technologies developed during the war. Architects were motivated not only by the interest in developing novel and amazing solutions, but also by a social concern, to lower the cost of building to provide housing for a larger percentage of American society. By mid $20^{\text {th }}$ century, the AIA had already assumed responsibility for some applied research, as Andrew Shanken describes:

In the postwar years the AIA enjoyed a vital partnership with the Producers' Council, a national organization of manufacturers ... . The Institute also provided important technical information on products through Theodore Coe's Technical Department. It created a system of filing manufacturers' pamphlets, which was indispensable in an economy of constantly proliferating products (Shanken 2005).

Looking to capitalize on these assets, the Department of E\&R set up an advisory service to act as a "listening post and reporting agency, clearing house and coordinating center, and the instigator of needed activities" (AlA 1947). Taylor and his colleagues spoke often of the architect's role in leading the building industry. They even lobbied the Producers Council to pay the Director's salary (AIA 1946)! More than this, they saw their work as a service to society, and argued that "because society as a whole will benefit through research for better shelter and environment, it should contribute major support through foundations, government agencies and elements of the building industry that are dependent upon the public for markets" (AIA Committee on Research for Architecture 1959).

The AIA's role, however, fell short of actual leadership. E\&R did not endorse the products developed through the research conducted under its auspices. Without such an endorsement, the building industry looked elsewhere for a safer return on their investment, either within their own research departments or in the academy. The Advisory Service, moreover, was rapidly dwarfed by the work of the Building Research Advisory Board (BRAB), a private, non-governmental, nonprofit organization under the auspices of the National Academy of Sciences. In 1954 Taylor and his staff conceded to this larger entity and discontinued their own service.

Under Taylor's direction the E\&R also worked to organize and disseminate knowledge developed within professional practice: architects' assessments of new building materials and systems. The project was neither efficient nor systematic, but it did reflect the organization of knowledge in many architectural firms and was under the complete control of the profession. In this program each architectural office was seen as a laboratory that produced knowledge that was valuable to the profession:

It would be impossible for the architect to conduct all of the studies of methods and new products that he needs. Yet, to some extent, each office is a laboratory where building problems are solved in terms of building methods, products and equipment. Each acts as a research center where knowledge of existing technology and imaginative exploration of new technical resources are combined in the service of building . . . (AIA 1956).

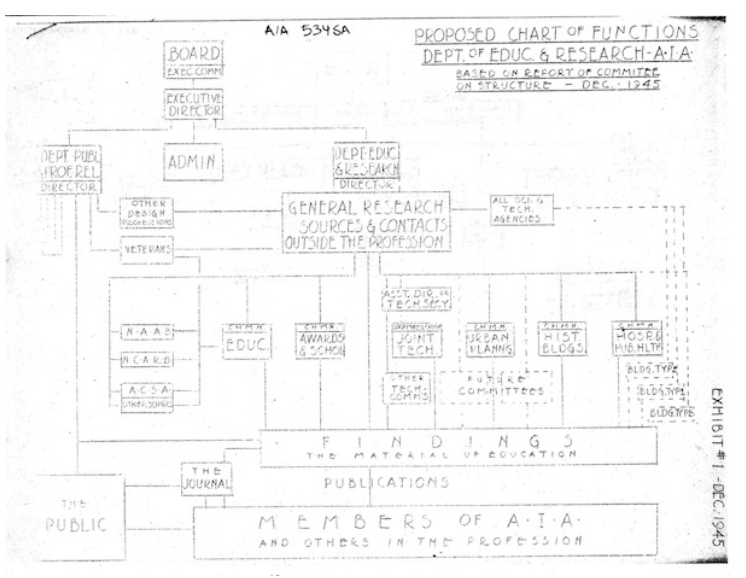

Figure 2: Chart of Proposed Functions of the Department of Education and Research, AIA 1945 Source: (AIA Archives, Washington, DC)

The Department's plan called for this information ("findings") to be filtered through "publications" and the AIA standing committees to the Department, where it would be organized and systematized before being disseminated to AIA members and the general public (see Figure 2.) In this scheme architectural practice became research; architects saw answering and compiling surveys as "doing research" (AIA 1959). In the 1950s the Department edited documents such as building type reference guides, technical reference guides, convention seminar reports, bibliographies, school plant studies and special technical articles. This material, disseminated through the AIA Bulletin, was important information for practicing architects. As with the advisory service, however, this publication project did not offer outside entities a return on their investment and was thus limited to the resources the AIA was willing and able to invest. Rather than become a leader in the field, the E\&R project competed with commercial projects with similar goals and with the research power of publications such as Architectural Record and P/A. An internal AIA memo from 1960, 
which lists the meager accomplishments, also indicates the frustrations involved in this competition:

1. Index of Architectural Information- several years of study and refinement by committee but awaiting financing to become a service operation.

2. Selection of material- building Products Registry- now going full blast. Going to press after six years of study. Board finally agreed to put some capital into it. Some things should happen on Specifications Service.

3. Specification Service - Similar background of study, surveys, etc. Recently renewed relationship with the Construction Specification Institute should pave the way for early activation of this service (AIA 1960).

\section{BASIC RESEARCH}

In the late 1950's the AIA expanded its interest to the more prestigious basic research. Once again, the AIA hoped to lead in this field, as Robert K. Merton, a member of the AIA Committee on Research for Architecture (CRA) explained:

If we raise our eyes from the ground on which we stand to look at the horizons that are even now visible, we will recognize that architecture is ready to enter a new phase in which it will, more systemically than ever before, formulate problems that in turn will activate new kinds of basic research in the underlying sciences. The first kind of basic research, then consists of generalizable investigations in the varied sciences fundamental to architecture, investigations which are in part stimulated by the formulations of problems arising in the field of architectural practice. A second kind of basic research in architecture is more nearly akin to what has been described as 'clinical research' in medicine. Here, the architect proceeds to synthesize the otherwise scattered bits of knowledge required to solve various types of architectural problems. Just as the medical internist is the 'generalist' in the field of health, so the architect is the 'generalist' in the field of design and construction. And just as clinical research in medicine only belatedly came to be recognized as basic investigation which was being carried forward by none of the underlying sciences, so too with architecture (Merton 1957).

Based on this conviction, the CRA, with the help of $E \& R$, organized a conference of "recognized authorities" from diverse disciplines such as sociology, psychology, architecture and planning (see Figure 3 and 4). The conference was held in Ann Arbor, Michigan in 1959, funded in part by the National Science Foundation (NSF). The objectives outlined for the conference reflect the AIA's centralized approach to basic research: one goal was to establish a "method of coordination of research to insure maximum

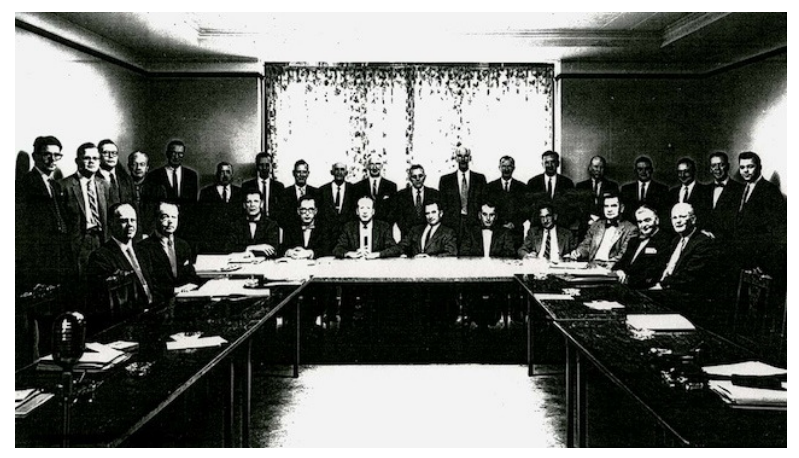

Figure 3: Participants at the 1959 AIA-NSF Conference on Research for Architecture in Ann Arbor, Michigan. Source: (AIA Archives, Washington, DC)

effectiveness of the total effort" (AIA 1958). This approach was cemented in the 1959 "Plan for Research for Architecture in the American Institute of Architects," which recommended founding a separate Department of Research:

The AIA Director of Research will be assisted and advised by the CRA and Advisory Council, and together must keep the program within manageable and expanding limits. Obviously this will require that projects be screened to determine whether they are researchable, whether they can be expected to yield useful material towards research goals, and if so, who should carry them out, how they can be financed and finally, through what medium results will be published. The plan outlines the recommended method or organizations, states the duties and qualification of the Director, and suggests financial responsibility and potential sources of funds (AIA Committee on Research for Architecture 1959).

The AIA plan was detailed and thorough, but it did not accord with the prevalent ideology of basic research and the accepted framework of decentralized research policy. Opposition came from within the profession of architecture. William W. Wurster, Dean of the College of Architecture at the University of California, Berkeley, supported a research policy modeled on Science the Endless Frontier (Bush 1945) and championed basic research conducted by independent researchers:

It has recently come to our attention that the research Committee of the AIA is thinking of establishing the position of Director of Architectural Research. I feel that the appointment of such a Director might well be contrary to the very idea of research and would do more harm than good. There is no holding the position of Director of Research for Chemistry, Physics, Psychology or Medicine and I can see no necessity for one in the architectural field. The appointment of a Director would lead Foundations to believe that architects were primarily interested in the development work rather than basic research. A true research approach is based upon the 
freedom of dedicated individuals to pursue their particular research interests and not in a directed program. These researchers should be supported in their work by a national organization, which could aid the individual and the profession by acting as a clearinghouse for information, and may help to locate funds for the pursuance of research (Wurster 1959).

Wurster, supported by his colleagues at Berkeley, worked to establish the academic apparatus for supporting decentralized research. The departmental research committee, which was staffed in rotation by almost all the faculty members, produced a 60-page manual outlining how research was to be encouraged and supported. The policy clearly stated that:

The selection of topics for research and the formulation of research programs rest essentially upon individual faculty members interested in pursuing or participating in the development of their own proposed programs (University of California 1959).

The Berkeley faculty also recognized, however, the need for a clear set of criteria for judging these projects, if any focus or "cumulative effort" was to be achieved. The committee recommended that faculty seek extramural funds, while also working to secure funding from the university, to provide incentives for researchers, to protect their freedom of choice of topics for research and to support the collection of data so as to avoid duplication.

While the discussion of basic research in the professional arena reached an impasse, the decentralized academic discipline of architecture, based on the ideology of basic research, continued to grow. But as the presence of architectural research on campuses expanded, architect-researchers began to be socialized into the academic profession, organizing their research according to academic priorities. At the same time, it became clear that the discipline could not achieve financial independence. The funding available in tenured positions, grants and fellowships is not enough to sustain the scale of research envisioned by the pioneers of the discipline. The academy's leadership, moreover, is often questioned by practitioners: a recurrent theme in architectural discourse is the gap between the profession and the discipline, and between the professional and the schools (Crosbie 1995; Kroloff 1996).

Walter Taylor left the AIA in 1960 to become Dean of the School of Architecture at Ohio State University. The AIA continued to promote and survey research for architecture; but as early as 1973, the authors of the AIA Research Survey acknowledged that the effort was stalled because architects, both in schools and in firms, did not recognize the need to share information (AIA 1973). In the early 1970s, the AIA established the AIA Research Corporation, which undertook the role E\&R had fulfilled in the 1950s. Similar entities, at the AIA and elsewhere, have revisited Taylor's centralized project.
FILE COPY

\section{Research For Architecture}

\author{
Condensed Report of An AIA Conference \\ Supported by The National Science Foundation \\ Ann Arbor, Michigan \\ March 10-12, 1959

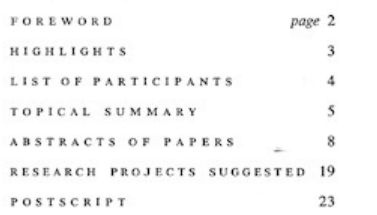 \\ 23 \\ Reprinted from the September and October 1959 issues of the \\ JOURAL OF THE AMERICAN INSTITUTE OF ABCHITECTS \\ 1735 New York Avenue, N.W., Washington 6. D. C. \\ Figure 4: AIA Report on the AIA-NSF Conference on \\ Research for Architecture 1959 Source: (AIA Archives, \\ Washington, DC)
}

\section{ON THE QUESTION OF LEADERSHIP}

Assigning leadership assumes a mechanism that assures "followership." Ideas of research, objectivity and social responsibility have changed since Taylor and his colleagues discussed taking leadership, but the decentralized model of research has remained. This model has its advantages as well as disadvantages. Despite the prosperity and the attendant building boom of the 1950s, the AIA Department of E\&R could not muster the resources to lead a comprehensive research project, in part because these resources were, as a matter of policy, scattered across institutions within the military-industrial complex. This holds true today, but we should think carefully before attempting to reshape that landscape. For example, "sustainability" can be examined either as a basic study in energy or as applied research into building materials - or in a "composite" approach, as a creative project of house design. We would probably not want to close off one of these approaches, in an effort to assign centralized leadership. Underlying the question of leadership, then, we will find a host of questions about current research policies, resources and opportunities - the realities that direct and shape our knowledge of architecture and architectural practice. 


\section{REFERENCES}

AIA 1947. Memorandum Re: Organization and Functioning of Department of Education and Research, AIA. Washington, DC, Publisher.

AIA 1958. Information for Invited Participants AIA-NSF Conference on Basic Architectural Research Dated 25 Nov. 1958. Washington, DC, Publisher.

AIA 1960. AIA Research for Architecture--10 Year Inventory (Draft) Dated 4 Feb. 1960. Washington, DC, Publisher.

AlA 1973. The American Institute of Architects Research Survey. Washington, DC, The American Institute of Architects.

AIA, 1954. Action on Report of Education and Registration Survey Commission. Washington, DC, Publisher.

AIA 1959. The Plan of Research for the American Institute of Architects September 8, 1959. Washington, DC, Publisher.

AlA,1956. Special Report \#4 A Statement on Architectural Research by the AIA Committee of Research. Washington, DC, Publisher.

AIA, 1959. Notes AIA Committee on Research (EXECCRX) Meeting: AIA- HQ, 20 May 1959. Washington, DC, Publisher.

AIA, 1946. Foreword Concerning Facts of Report of the Committee on the Structure of the Institute. The AIA Bulletin.

AIA, n.d.. Expanded Program. Washington, DC, Publisher.

Anderson, S. 1997. The New Empiricism- Bay Region Axis: Kay Fisker and Postwar Debates on Functionalism, Regionalism, and Monumentality." Journal of Architectural Education, 50(3): 197-207.

Barr, J., Alfred H. , Hitchcock, H.-R. et al. 1948. "What Is Happening to Modern Architecture?" The Bulletin of the Museum of Modern Art, 15(3): 4-20.

Bender, T. 1997. Politics, Intellect, and the American University, 1945-1995. American Academic Culture in Transformation, Fifty Years, Four Disciplines. T. Bender and C. E. Schorske. Princeton, NJ, Princeton University Press.

Bush, V. 1945. Science the Endless Frontier A Report to the President on a Program for Postwar Scientific Research. Washington, DC, United States Government Printing Office.
Creighton, T. H. 1954. A Suggested Program of Action for the AIA. Progressive Architecture (December).

Crosbie, M. J. 1995. The Schools: How They're Failing the Profession (and What We Can Do About It). Progressive Architecture. September: 47-51.

Friedmann, J. 1996. Two Centuries of Planning Theory: An Overview. Explorations in Planning Theory. S. J. Mandelbaum, L. Mazza and R. W. Burchell. New Brunswick, NJ, Center for Urban Policy Research Rutgers, The State University of New Jersey.

Geiger, R. L. 1993. Research and Relevant Knowledge: American Research Universities Since World War II. New York, Oxford University Press.

Graham, H. D. and Diamond, N. 1997. The Rise of the American Research University Elites and Challengers in the Postwar Era. Baltimore, MD, The Johns Hopkins University Press.

Gropius, W. 1951. Lecture on Architectural Education." Journal of Architectural Education 6: 78-87.

Kleinman, D. L. 1995. Politics on the Endless Frontier Postwar Research Policy in the United States. Durham and London, Duke University Press.

Kroloff, R. 1996. How the Profession is Failing the Schools Architecture August: 92-93.

Merton, R. K. 1957. Letter to Walter E. Campbell, AIA Chairman, Committee on Research From Robert K. Merton About: Some Preliminary Notes on Problems and Prospects of a Proposed Conference on Basic Research in Architecture Dated: 4 November, 1957. Washington, DC, Publisher.

Shanken, A. M. 2005. Between Brotherhood and Bureaucracy: Joseph Hudnut, Louis I. Kahn and the American Society of Planners and Architects. Planning Perspectives 20(April): 147-175.

Taylor, W. A. 1954. Research in Architectural Design Remarks by Walter A. Taylor, Director, Department of Education \& Research, The AIA at the Conference on Hospital Planning, Chicago, September 23, 1954. Washington, DC, Publisher.

University of California, D. o. A. B. 1959. Policy Statement on Architectural Research for the Department of Architecture of the University of California January 1959. Berkeley, CA, Publisher.

Vanderburgh, D. J. T. and Ellis, W. R. 2001. A Dialectics of Determination: Social Truth Claims in Architectural Writing, 1970-1995. The Discipline of Architecture. A. Piotrowski and J. W. Robinson. Minneapolis, University of Minnesota Press.

Wright, G. 2008. Modern Architectures in History USA. London, Reaktion Books. 
Wurster, W. W. 1954. The Architect at Mid-Century Evolution and Achievement A Brief Report on the Educational Recommendations Outlined in the Above by William Wilson Wurster, Dean of Architecture University of California, Berkeley Dated 15 June, 1954. Berkeley, CA, Publisher.

Wurster, W. W. 1959. Letter to Mr. Walter Campbell, AIA, Chairman, AIA Research Committee dated 25 November 1959. Berkeley, CA, Publisher. 